\title{
DEMOTIVATING FACTORS OF EFL LEARNERS OF INDONESIAN UNDERGRADUATE STUDENTS DURING PANDEMIC COVID-19: GENDER DIFFERENCES
}

\author{
IMAM SANTOSA, M.PD \\ STKIP Media Nusantara Citra \\ imamsantosa1987@gmail.com \\ YASIR RIADY,S.S.,M.HUM \\ Universitas Terbuka \\ yasir@ecampus.ut.ac.id
}

DOI : 10.29300/ling.v7i1.4933

Received: June $4^{\text {th }}, 2021$

Accepted: June $27^{\text {th }}, 2021$

Published: July $14^{\text {th }}, 2021$

\begin{abstract}
Pandemic covid-19 precedes education to adapt with this disruptive situation. The needs of teaching and learning continuity suggests online learning as one of the solutions along with its challenge. This study aim to investigate whether gender differences influence demotivating factors of EFL Learners of Indonesian Undergraduate Student during pandemic covid-19 situation Surveys design was utilized to verify the hypothesis in this research. On the basis of Kikuchi's (in press) qualitative study, this study employed 34-item questionnaire that consist of five categories;((a) Course Books, (b) Inadequate School Facilities, (c) Test Scores, (d) Noncommunicative Methods, and (e) Teachers' Competence and Teaching Styles) to gather quantitative data. Having cluster random sampling as sampling technique, the participants were $368 \mathrm{EFL}$ Learners of Indonesian Undergraduate Student from private universities in Jakarta. The findings of the research revealed that gender did not influence demotivation factors on online learning during pandemic situation. However, the finding indicated the absence of face-to-face teacher in online learning significantly influence demotivating factors on learning English, as non-communicative approach and teacher performance being the most cited factors. Additionally, the result of the study can be the basis of further research on demotivating factors in learning English.
\end{abstract}

Keywords: Demotivation, Kikhuci \& Sakai, Online Learning, Covid-19, Gender differences

\section{INTRODUCTION}

Pandemic covid-19 precedes education to adapt with this disruptive situation. The needs of teaching and learning continuity suggests online learning as one of the solutions along with its challenge. Mahyoob (2020) stated the problems of online learning comes from 3 major factors that is technical, academic, and communication challenges. In addition, Mahyoob suggested that those three factors lead dissatisfaction of eLearning. Furthermore, online learning in pandemic situation also instigates student anxiety (Hasanah et al., 2020; Moghanibashi-Mansourieh, 2020; Sundarasen et al., 2020). The problem of students' 
dissatisfaction needs to be addressed by identifying how to encourage student's motivation in online class.

Perspectives to encourage student has been conducted to tackle student problem. Fuentes Hernández et al (2020) argued that teacher mediation through synchronous communication positively impacted student motivation level. Besides, (Muslimin \& Harintama, 2020) believed that the utilization of social media affected student engagement in online classroom. Likewise, Kaharuddin et al. (2020) findings exhibited that incorporating technology and culture in classroom learning impacted student motivation in the classroom. Also, Qunfei et al. (2020) listed the factors that may influenced student motivation in online learning. those are scientific and reasonable online English learning standard environment, appropriate guidance for autonomous learning, reasonable organization of online teaching methods, effective communication among learners and teachers' timely and effective evaluation and feedback, as well as other incentive measures.

However, the implementation of the methods to encourage student motivation may fail because of the different factors influencing the result such as, culture, geographical, student's characteristic etc. hence, instead of selecting the method to motivate student, the problems that caused student's demotivation need to be addressed. By identifying the factors lead student demotivation, proper action and method could successfully be implemented. As stated by Dornyei \& Ushioda (2013) demotivation factor has been neglected as motivation of the student is the main focus. Demotivation (Dörnyei \& Ushioda, 2013) may not imply that any of the positive forces that contributed to a behaviour's motivational foundation have been removed.; rather, and some other positive motivations may still be operational, it is just the resultant cogency that has been diminished by a strong negative portion. The negative equivalents to, respectively, are demotivation. A motivation encourages an action's likelihood, while a demotivation reduces it. A demotivated learner is someone who was originally inspired to learn but has lost the drive due to external negative stimuluses at some point during the learning process.

Discussion focusing on demotivation has been previously conducted. Shin \& Kim (2017) investigates the factor of demotivation on elementary students. The study classified the demotivating factor into Negative attitude towards the L2 learning assessments, Negative attitude towards the L2, Mismatch of learning materials, The compulsory nature of the L2 study, Negative attitude towards the L2 community, Reduced self-confidence, Negative influence from instructors and Inadequate school facilities. The result revealed that negative attitude toward the L2 learning assessments outnumbered other demotivating factors. Moreover, the study of demotivation also conducted in the middle school level. Li (2019) The conducted a survey to discover more about the variables that lead to demotivation in EFL Linguists: Journal of Linguistics and Language Teaching Vol. 7, No. 1, July 2021 
students in middle school. The result indicated that the lack of interest in learning, among other internal and external factors, such as decline in self-confidence, poor learning abilities, lack of learning strategies, difficulty of textbook articles, and rare use of multi-media in English classes.

Additionally, the study of demotivation in higher level from the previous study administered in Korean School. Song \& Kim (2017) investigated the variables that influence Korean high school EFL students' demotivation and demotivation. The study focused on the changing of student motivation on learning English since kindergarten until high school. The result revealed that the majority of the participants turn out to be most demotivated in junior high school, mainly as a result of external factors, such as ineffective teaching methods, learning difficulty, and social pressure. In addition, Kim \& Kim (2016) executed the research of demotivating factors across different level of school, kindergarten to universities level. The study revealed that two main common factors (1) English learning difficulty and (2) teacherrelated factors. More specifically, English learning difficulty relates to students' struggles with grammar and vocabulary, whereas teacher-related factors involve the teachers' behaviour and teaching styles. However, the previous study related to demotivation did cover the one system teaching of activities, that is face to face teaching activities. Thus, this study wants to fill the gap to investigating the demotivating factors that influenced EFL student in online learning during pandemic covid-19 situation.

\section{Online Learning in Pandemic Covid-19}

During COVID-19, as mandated by minister of education of Indonesia, face to face on teaching and learning activity needed to be halted to minimize the spread of the virus. Students and teachers encounter teaching and learning activities through technology. Distance education has become more available due to fast technical advances (McBrien et al., 2009). "Most of the words (for example, online learning, open learning, web-based learning, computer-mediated learning, blended learning, and m-learning) have in common the sovereignty to learn from anywhere, at any moment, in any rhythm, and with any means" (Cojocariu et al., 2014). Moreover, Online learning may be conceived of as a platform for allowing the teaching-learning process more student-cantered, creative, and dynamic. "Learning experiences in synchronous or asynchronous environments using various devices with internet access" is how online learning is described. Students can learn and communicate with professors and other students from anywhere in these environments (Singh \& Thurman, 2019). Also, As mentioned by Anderson (2004), online learning enhanced 
interaction between teacher and student without constraint. In conclusion, Online learning served as suitable media for teaching and learning activities in recent condition.

There are variety of technologies accessible for online education but it also generates difficulties and problems as lack of readiness on this fast changing. Joosten \& Cusatis (2020) examined the factor that influenced readiness on online learning. the finding showed that Online learning efficacy, online work skills, and socialization were the major part of factors. Besides, (Kundu \& Bej, 2021) investigated student readiness on sudden shift on education. The result indicated the unreadiness of the student to adapt to this extraordinary alteration. The student experienced fear, insecurities, and numerous challenges. However, the problem of readiness to face sudden shift could be deciphered by the teacher. The responsibilities of teacher become the major factor of teacher readiness on online learning (Lapada et al., 2020). The result also was supported by Nurkhamidah \& Isnaini (2020) that revealed the readiness of the teacher was higher than student.

Student appears as the side who procured numerous intricacies on online learning. Adnan (2020) pointed out the absence of teacher on face-to-face classroom leads students feel less motivation on learning. Hussein et al. (2020) examined the challenge on implementation of online learning. The result implied distraction and reduced focus, heavy workload, problems with technology and the internet, and insufficient support from instructors and colleagues were the most recurrent negative aspects. More In addition, Those aspect, again, swayed student motivation on learning. Moreover, Chung et al. (2020) stated beside insufficient facility to held online learning during pandemic Covid-19, self-directed learning became barrier. The students had problem $\mathrm{t}$ set clear goals in online and need additional guidance from teacher. Besides, online learning created problem for student emotional. The student faced emotional disorder because of lack of social interaction during online learning. The declined of student motivation also existed in online learning activities (Yustina et al., 2020).

Learning motivation turns out to be imperative factor to face the challenge in online learning. various methods and approaches have been conducted to stimulate student motivation. Susilowati \& Supriyono (2020) utilize WhatsApp to improve students' motivation. Social regulation-based online learning approach used to improve students' learning accomplishments and learning enthusiasms (Hwang et al., 2021). Moreover, Zhu et al. (2020) employed self-regulated learning approach to increase student motivation in online learning.

However, the implementation of the methods to encourage student motivation may fail because of the different factors influencing the result such as, culture, geographical, student's characteristic etc. hence, instead of selecting the method to motivate student, the Linguists: Journal of Linguistics and Language Teaching Vol. 7, No. 1, July 2021 
problems that caused student's demotivation need to be addressed. By identifying the factors lead student demotivation, proper action and method could successfully be implemented. As stated by Dornyei \& Ushioda (2013) demotivation factor has been neglected as motivation of the student is the main focus.

\section{Demotivation}

Demotivation defined as the condition of deficiency of effort, need and aspiration in involving teaching and learning activity (Aydin, 2012). Moreover, Dornyei (2013) described demotivation as external factors that lessen the motivational basis of a behavioural action or an in-progress action. Following that, the focus of demotivation on this study is as mentioned of Dornyei which see demotivation as external factor, developed by Kikuchi and Sakai (2009) and extended by Krishnan \& Pathan (2013).

Investigation on demotivation administered on different basis and result. As mentioned by Gorham and Christophel (1992), demotivation described as behavioural act toward teaching activities. The study classified the act into 5 classifications. That are Dissatisfaction with grading and assignments, boring, bored, unorganized and unprepared teacher, The dislike of the subject area, The inferior organization of the teaching material and The teacher being unapproachable, self-centred, biased, condescending and insulting. Furthermore, Oxford (2014) warned the involvement of teacher that trigger demotivation on learner. The behaviour of the teacher that influenced student's demotivation are the teacher's personal relationship with the student, The teacher's attitude towards the course or the material, Style conflicts between teachers and students, and the nature of the classroom activities.

The growth of study on demotivation on teaching activity altered on focusing to student perspective. Dörnyei (1998) concerned on 9 types of negative factors influencing student's motivation or demotivating student in learning activities. They are The teacher (personality, commitment, competence, teaching method), Inadequate school facilities (group is too big or not the right level; frequent change of teachers), Reduced self-confidence (experience of failure or lack of success), Negative attitude towards the L2, Compulsory nature of L2, Interference of another foreign language being studied, Negative attitude towards L2 community, Attitudes of group members, and Coursebook. This research stimulated Kikuchi and Sakai to explore further about demotivating factors.

Kikuchi and Sakai (Kikuchi \& Sakai, 2009) examined factors that influencing student demotivation among upper secondary school in Japan. The study focused on investigating the factors that demotivate student on learning English and also the differences in demotivating 
factors. The factors derived by Kikuchi and Sakai consisted of 6 classifications; teacher behavior (5 items), classroom environment (8 items), grammar-based teaching (6 items), course contents and teaching materials ( 7 items), lack of self-confidence (4 items), and effects of low-test score (5 items).

Past research has indicated demotivating factors derives from different external and internal variables. The external factors are such teacher behaviour, ineffective teaching methods, learning difficulty, and social pressure, negative attitudes of the classmates, personal issues, class characteristics, test anxiety, failure experiences, and education system, a lack of speaking practice, and a discrepancy between their desired level and their perceived 'stagnant' level (Evans \& Tragant, 2020; Han et al., 2019; Song \& Kim, 2017).

\section{Gender differences in learning English}

Previous studies indicated there are differences on learning EFL based on gender differences. Faridizad \& Simin (2015) found that gender difference significantly influences the use of language learning strategies. The result indicated the tendency of using more language learning strategy by Female learners than males. In addition, Saranraj et al (2016) perceived gender as the factors influences interest, positive behaviour, and performance. The result showed female have more interest, positive behaviour, and better performance. In addition, Rajendran et al (2020) observed gender-based variation in motivation, engagement and interaction behaviour of school students. the result indicated that female students are highly motivated, desires to intermingle through the app more frequently and devote more time on app compared to male students. Feng et al (2013) exposed the significant differences based on gender on students' learning motivations. These differences are task value and control beliefs about learning. moreover, Gender influenced subtle age differences in kinaesthetic and tactile styles in learning English through technology (Lee et al., 2016). In summary, gender differences influence EFL students in the aspect of learning EFL.

Based on the discussion above, investigating factors of demotivation among the student need to be conducted. Therefore, the present study was carried out to answer question:

Do Male and female students significantly differ on demotivating factors on Learning EFL during pandemic covid-19?

\section{METHOD}

In this study the authors used survey as a research design. According to Creswell (2003), survey designs are procedures in quantitative research in which you administer a survey or questionnaire to a small group of people (called the sample) to identify trends in Linguists: Journal of Linguistics and Language Teaching Vol. 7, No. 1, July 2021 
attitudes, opinions, behaviors, or characteristics of a large group of people (called the population). In conducting this study researchers need to consider the social point of view such as students' perceptions of demotivating factors in learning English through online learning in pandemic covid 19. To support this qualitative approach, researchers need to conduct interviews via online forms without directly observing the participants due to pandemic which makes it impossible for students to carry out learning activities in the classroom.

\section{Respondents}

To explore whether gender significantly influence demotivating factors for EFL undergraduates' students in Indonesia online learning during pandemic covid 19, the participants of the study are undergraduate student who experiencing online learning during pandemic covid 19. The number of participants is 368 students of private universities Jakarta. The technique or sampling used in this research is Cluster Random Sampling. According to Azwar (2010) the purpose of a cluster (Cluster Random Sampling) is to perform randomization on groups, not on individual subjects. By using cluster random sampling, the result of the study represented the population of the study.

\section{Instruments}

This study exploits questionaries to examine Demotivating factors of EFL Learners of Indonesian Undergraduate Student in online learning during pandemic covid-19. The questionaries items were adopted from Kikuchi and Sakai model (2009). The questionnaires consisted 34 item which has been previously tested on its reliability. The questions divided into;((a) Course Books, (b) Inadequate School Facilities, (c) Test Scores, (d) Noncommunicative Methods, and (e) Teachers' Competence and Teaching Style. The result of reliability has value of 0.761 Alpha Cronbach. The questions based on the Kikuchi and Sakai suggested framework.

\section{Procedures}

The questioner was delivered by online form to the participant of the study on Indonesian to ensure the respondents don't have bias from language barriers. A pilot test study was conducted to check the used questionnaire with regard to the strength and consistency of its internal reliability. The questionnaire was completely valid and reliable without a doubt, as the results of the reliability coefficient for the pilot study (Cronbach's alpha) was measured at 0.88 . 


\section{Data analysis}

After collecting the data, Statistical Package for the Social Sciences (SPSS) program was utilized to analyse of students' response, T-test and frequency tests used to answer research question.as pre analysis, Kolmogorov-Smirnov test utilized to perform normality test and Levene test to perform homogeneity test. SPSS statistical inferential techniques were utilized to test demotivating factors according to gender. In addition, an independent T-test was performed at a 0.05 level of significance to examine differences between the male and female respondents. A p value of less than alpha (0.05) was considered as a significant difference between the groups.

\section{FINDINGS AND DISCUSSION}

\section{Findings}

Table 1 presents descriptive result of each item which consisted of 34 items.

\begin{tabular}{|c|c|c|c|c|}
\hline $\begin{array}{c}\text { No. } \\
\text { Items }\end{array}$ & Strongly Agree & Agree & Disagree & Strongly disagree \\
\hline 1 & $18.57 \%$ & $55.97 \%$ & $23.61 \%$ & $1.86 \%$ \\
\hline 2 & $14.85 \%$ & $67.11 \%$ & $17.51 \%$ & $0.53 \%$ \\
\hline 3 & $23.87 \%$ & $65.25 \%$ & $10.08 \%$ & $0.80 \%$ \\
\hline 4 & $13.53 \%$ & $59.15 \%$ & $24.93 \%$ & $2.39 \%$ \\
\hline 5 & $40.05 \%$ & $54.64 \%$ & $4.24 \%$ & $1.06 \%$ \\
\hline 6 & $13.53 \%$ & $54.38 \%$ & $29.97 \%$ & $2.12 \%$ \\
\hline 7 & $11.67 \%$ & $54.91 \%$ & $30.77 \%$ & $2.65 \%$ \\
\hline 8 & $16.98 \%$ & $50.93 \%$ & $28.38 \%$ & $3.71 \%$ \\
\hline 9 & $17.51 \%$ & $43.77 \%$ & $34.48 \%$ & $4.24 \%$ \\
\hline 10 & $11.94 \%$ & $48.81 \%$ & $36.60 \%$ & $2.65 \%$ \\
\hline 11 & $11.94 \%$ & $44.03 \%$ & $36.60 \%$ & $7.43 \%$ \\
\hline 12 & $29.97 \%$ & $32.36 \%$ & $27.59 \%$ & $10.08 \%$ \\
\hline 13 & $11.67 \%$ & $54.91 \%$ & $30.77 \%$ & $2.65 \%$ \\
\hline 14 & $21.75 \%$ & $50.13 \%$ & $23.87 \%$ & $4.24 \%$ \\
\hline 15 & $33.69 \%$ & $35.54 \%$ & $20.69 \%$ & $10.08 \%$ \\
\hline 16 & $12.47 \%$ & $44.03 \%$ & $38.73 \%$ & $4.77 \%$ \\
\hline 17 & $10.61 \%$ & $46.95 \%$ & $38.20 \%$ & $4.24 \%$ \\
\hline 18 & $10.08 \%$ & $48.54 \%$ & $37.40 \%$ & $3.98 \%$ \\
\hline 19 & $8.49 \%$ & $63.66 \%$ & $25.99 \%$ & $1.86 \%$ \\
\hline 20 & $8.22 \%$ & $50.13 \%$ & $37.40 \%$ & $4.24 \%$ \\
\hline 21 & $6.10 \%$ & $21.75 \%$ & $61.27 \%$ & $10.88 \%$ \\
\hline 22 & $10.08 \%$ & $42.44 \%$ & $42.18 \%$ & $5.31 \%$ \\
\hline 23 & $10.34 \%$ & $38.20 \%$ & $41.38 \%$ & $10.08 \%$ \\
\hline 24 & $10.88 \%$ & $48.01 \%$ & $35.81 \%$ & $5.31 \%$ \\
\hline 25 & $10.34 \%$ & $29.18 \%$ & $51.72 \%$ & $8.75 \%$ \\
\hline 26 & $11.14 \%$ & $47.48 \%$ & $36.60 \%$ & $4.77 \%$ \\
\hline 27 & $2.92 \%$ & $17.77 \%$ & $63.93 \%$ & $15.38 \%$ \\
\hline 28 & $2.65 \%$ & $15.65 \%$ & $64.72 \%$ & $16.98 \%$ \\
\hline 29 & $11.94 \%$ & $27.06 \%$ & $45.09 \%$ & $15.92 \%$ \\
\hline 30 & $2.65 \%$ & $9.81 \%$ & $58.89 \%$ & $28.65 \%$ \\
\hline 31 & $3.45 \%$ & $13.00 \%$ & $67.64 \%$ & $15.92 \%$ \\
\hline 32 & $1.59 \%$ & $7.69 \%$ & $59.15 \%$ & $31.56 \%$ \\
\hline 33 & $1.86 \%$ & $10.61 \%$ & $58.36 \%$ & $29.18 \%$ \\
\hline 34 & $1.06 \%$ & $12.20 \%$ & $64.46 \%$ & $22.28 \%$ \\
\hline
\end{tabular}

Linguists: Journal of Linguistics and Language Teaching Vol. 7, No. 1, July 2021 
Then, descriptive statistic was carried out. The result on the table 2

Table 2. The Descriptive Result

\begin{tabular}{|l|l|l|l|l|l|}
\hline Descriptive Statistics & N & Minimum & Maximum & Mean & Std. Deviation \\
\hline & 195 & 63 & 111 & 87.84 & 9.631 \\
\hline Demotivating Factors on female & 173 & 61 & 117 & 86.34 & 10.667 \\
\hline Demotivating Factors on male & 173 & & & & \\
\hline Valid N (listwise) & & & & & \\
\hline
\end{tabular}

Based on the data in Table 2, it indicated that the average value of female demotivation is $(\bar{x}=87,84)$ with a standard deviation of 9.63. In the other hand, The average score of male demotivation is $(\bar{x}=86,34)$ with a standard deviation of 10,67 . These results indicate that from a total of 368 samples, the average score for demotivation is high, namely in female students.

Before performing independent T-test, Kolmogorov-Smirnov test utilized to perform normality test and Levene test to perform homogeneity test. The results of the normality test on student demotivating factors data in online learning during pandemic Covid-19 are presented in the following table:

Table 3. Normality Test

\begin{tabular}{|c|c|c|c|c|c|c|}
\hline \multicolumn{7}{|c|}{ Tests of Normality } \\
\hline & \multicolumn{3}{|c|}{ Kolmogorov-Smirnov $^{\mathrm{a}}$} & \multicolumn{3}{|c|}{ Shapiro-Wilk } \\
\hline & Statistic & $\overline{\mathrm{Df}}$ & Sig. & Statistic & $\overline{\mathrm{Df}}$ & Sig. \\
\hline female & .065 & 173 & .068 & .980 & 173 & .015 \\
\hline male & .063 & 173 & .093 & .985 & 173 & .057 \\
\hline
\end{tabular}

The data demonstrated the results of the normality test using the Kolmogrov-Smirnov test on demotivating factors data, female students obtained a statistical value of 0.065 , df $=$ 173 and significance $(\mathrm{sig})=0.068$. This means that the value of sig $>0.05$ or $0.068>0.05$, so it can be concluded that the demotivating factors of female students with 173 samples is normally distributed. The demotivating data of male students obtained a statistical value of $0.063 \mathrm{df}=173$ and significance $(\mathrm{sig})=0.093$. This means that the value of sig $>0.05$ or $0.093>0.05$, so it can be concluded that the demotivating factors of male students is normally distributed.

Furthermore, the results of the homogeneity test of data on demotivating factors of students in online learning during pandemic Covid-19 are presented in the following table: 
Table 4. the results of the homogeneity test of data

\begin{tabular}{|l|l|l|l|l|l|}
\hline \multicolumn{2}{|l|}{ Test of Homogeneity of Variance } \\
\hline \multirow{4}{*}{\begin{tabular}{l} 
Demotivating factors \\
\hline \multirow{5}{*}{}
\end{tabular}} & Levene Statistic & df1 & df2 & Sig. \\
\cline { 2 - 7 } & Based on Median & .594 & 1 & 366 & .441 \\
\cline { 2 - 7 } & Based on Median and with adjusted df & .569 & 1 & 366 & .451 \\
\cline { 2 - 7 } & Based on trimmed mean & .567 & 1 & 366 & .452 \\
\hline
\end{tabular}

The results of the data homogeneity test using Levene's test obtained the value of $\mathrm{F}=$ 0.594 , df $1=1$, df $2=366$, and the significance value $(\mathrm{sig})=0.441$. Thus, the value of sig $>$ 0.05 or $0.441>0.05$ so that the data in the sample group has the same or homogeneous variance.

Table 5. Independent Sampe Test

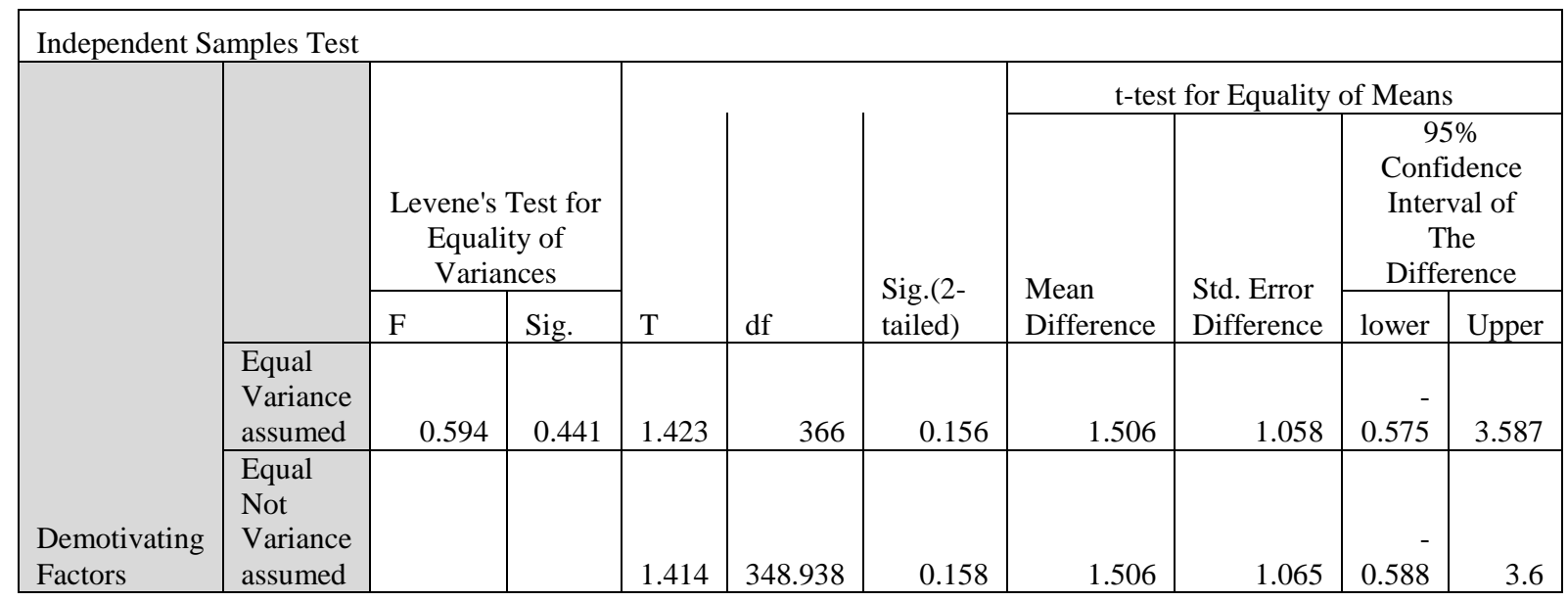

Based on table 5 above, in the t-test column for equality of means, the $t$ value $=0.156$ with $\mathrm{df}$ 366 and sig (2-tailed) of 0.156 or p-value $=0.156 / 2=0.078$, then $p-$ value $>0,05$ atau $0,078>$ 0,05 . Thus, it can be concluded that $\mathrm{H} 0$ is accepted. This means that there is no significant difference in the average demotivating factors score between male and female students in online learning during pandemic situation.

\section{Discussion}

Based on the data above, the finding indicated that gender did not influence demotivation factors on online learning during pandemic situation. The result contradicted with the findings of previous research that showed gender differences influence factors in learning English Previous studies indicated there are differences on learning EFL based on gender differences. (Faridizad \& Simin, 2015) (Saranraj et al., 2016) (Rajendran et al., 2020) (Feng et al., 2013)(Lee et al., 2016). However, the result of the study is in line with Adnan 
(2020) that believed the absence of teacher in face to face classroom leads affected students motivation on learning. this is exposed by data taken from non-communicative approach by the teacher in online learning as shown below.

Table 6. Data Taken from Non-Communicative Approach

\begin{tabular}{|c|c|c|c|c|}
\hline \multicolumn{5}{|c|}{ NON COMMUNICATIVE APPROACH } \\
\hline No. & Strongly Agree & Agree & Disagree & Strongly disagree \\
\hline 1 & $18.57 \%$ & $55.97 \%$ & $23.61 \%$ & $1.86 \%$ \\
\hline 2 & $14.85 \%$ & $67.11 \%$ & $17.51 \%$ & $0.53 \%$ \\
\hline 3 & $23.87 \%$ & $65.25 \%$ & $10.08 \%$ & $0.80 \%$ \\
\hline 4 & $13.53 \%$ & $59.15 \%$ & $24.93 \%$ & $2.39 \%$ \\
\hline 5 & $40.05 \%$ & $54.64 \%$ & $4.24 \%$ & $1.06 \%$ \\
\hline 6 & $13.53 \%$ & $54.38 \%$ & $29.97 \%$ & $2.12 \%$ \\
\hline 7 & $11.67 \%$ & $54.91 \%$ & $30.77 \%$ & $2.65 \%$ \\
\hline Total & $19.44 \%$ & $58.77 \%$ & $20.16 \%$ & $1.63 \%$ \\
\hline
\end{tabular}

Based the data above, means of strongly agree is $19.44 \%$ and agree is 58.77 . It can be concluded, the respondents majorly $(78.21 \%)$ believed non communicative approach caused by the absence of the teacher in the face-to-face situation influence demotivating factor in learning English during pandemic covid-19. It is also in line with (Yustina et al., 2020) that declared that online learning impact student motivation on learning English.

In first question of non-communicative approach category, the lack of opportunity to communicate in English cited as one of the demotivating factors on learning English during pandemic. In addition, based on the open-ended response, [29] it is really hard to practicing English without face-to-face communication and guidance from the lecturer. Lack of social interaction reduced student eagerness to learn English. The result is in line with Irawan et al. (2020) that believed students need physical social interaction among students and teacher in the classroom. Lack of social interaction lead emotional disorder during online learning during pandemic Covid-19. That also align with Chung et al (2020) that stated self-directed learning became barrier on online learning during pandemic covid-19. The students had problem to set clear goals in online learning and need additional guidance from teacher.

\section{CONCLUSION}

Based on the findings and discussion, gender difference did not influence demotivation factors on online learning during pandemic situation. The result conflicted with the findings of preceding research that showed gender disparities shape demotivating factors 
in learning English Previous studies indicated there are differences on learning EFL based on gender differences. (Faridizad \& Simin, 2015) (Saranraj et al., 2016) (Rajendran et al., 2020) (Feng et al., 2013)(Lee et al., 2016). However, the result of the study supported Adnan (2020) that believed the absence of teacher in face to face classroom leads affected students motivation on learning. The respondent majorly (78.21\%) believed non communicative approach caused by the absence of the teacher in the face-to-face situation influence demotivating factor in learning English during pandemic covid-19. It is also in line with (Yustina et al., 2020) that affirmed that online learning impact student motivation on learning English. It can be inferred the existence of face-to-face teacher in the teaching and learning activity is crucial.

\section{REFERENCES}

Azwar, Saifuddin. (2010). Metode Penelitian. Yogyakarta: Pustaka Pelajar

Adnan, M. (2020). Online learning amid the COVID-19 pandemic: Students perspectives. Journal of Pedagogical Sociology and Psychology. https://doi.org/10.33902/jpsp.2020261309

Chung, E., Noor, N. M., \& Vloreen Nity Mathew. (2020). Are you ready? an assessment of online learning readiness among university students. International Journal of Academic Research in Progressive Education and Development.

Cresswell, J. W. (2003). Qualitative, Quantitative. and Mixed Methods Approaches. In Research Design, Second Edition. https://doi.org/10.3109/08941939.2012.723954

Faridizad, A., \& Simin, S. (2015). Exploring the relationship between learners gender differences and communication apprehension considering the class participation in Iranian EFL context. International Letters of Social and Humanistic .... https://www.learntechlib.org/p/177236/

Feng, H. Y., Fan, J. J., \& Yang, H. Z. (2013). The relationship of learning motivation and achievement in EFL: Gender as an intermediated variable. In Educational Research International. erint.savap.org.pk. http://www.erint.savap.org.pk/PDF/Vol.2(2)/ERInt.2013(2.2-07).pdf

Irawan, A. W., Dwisona, D., \& Lestari, M. (2020). Psychological Impacts of Students on Online Learning During the Pandemic COVID-19. KONSELI : Jurnal Bimbingan Dan Konseling (E-Journal). https://doi.org/10.24042/kons.v7i1.6389

Lee, C., Yeung, A. S., \& Ip, T. (2016). Use of computer technology for English language learning: do learning styles, gender, and age matter? Computer Assisted Language Learning. https://doi.org/10.1080/09588221.2016.1140655

Rajendran, R., Banerjee, G., Pathak, D., \& Sivamohan, S. (2020). Impact of gender on motivation, engagement and interaction behavior in mobile assisted learning of english. Proceedings - IEEE 20th International Conference on Advanced Learning Technologies, ICALT 2020. https://doi.org/10.1109/ICALT49669.2020.00075

Linguists: Journal of Linguistics and Language Teaching

Vol. 7, No. 1, July 2021 
Saranraj, L., Khan, Z. A., \& Zafar, S. (2016). Influence of motivational factors and gender differences on learning English as a second language: A case of engineering students from rural background. In Indian Journal of Science and .... researchgate.net. https://www.researchgate.net/profile/Saranraj-

Loganathan/publication/311497129_Influence_of_Motivational_Factors_and_Gender_D ifferences_on_Learning_English_as_a_Second_Language_A_Case_of_Engineering_Stu dents_from_Rural_Background/links/584f97f308aeb989252

Yustina, Y., Halim, L., \& Mahadi, I. (2020). The Effect of "Fish Diversity" Book in Kampar District on the Learning Motivation and Obstacles of Kampar High School Students through Online Learning during the COVID-19 Period. Journal of Innovation in Educational and Cultural Research. https://doi.org/10.46843/jiecr.v1i1.2 